\title{
Distribution and genetic diversity of Blastocystis subtypes in various mammal and bird species in northeastern China
}

\author{
Jianguang Wang ${ }^{\dagger}$, Baiyan Gong ${ }^{\dagger}$, Xiaohua Liu, Wei Zhao, Tong Bu, Weizhe Zhang, Aiqin Liu and Fengkun Yang*
}

\begin{abstract}
Background: Blastocystis is one of the most common intestinal parasites in humans and animals worldwide. At least 17 subtypes have been identified in mammals and birds. In China, although some studies have reported the occurrence of Blastocystis in humans and animals, our understanding of the role of animals in the transmission of human blastocystosis is only superficial due to a paucity of available molecular data. The aim of the present study was to understand infection rates of Blastocystis and the distribution and genetic diversity of subtypes in various mammal and bird species in northeastern China, as well as to assess the zoonotic potential of Blastocystis isolates.
\end{abstract}

Methods: A total of 1265 fresh fecal specimens (1080 from ten mammal species and 185 from eight bird species) were collected in Heilongjiang, Liaoning and Jilin provinces of China. Each specimen was examined for the presence of Blastocystis by PCR amplification and sequence analysis of the partial SSU rRNA gene.

Results: Fifty-four specimens (4.3\%) were positive for Blastocystis. Birds (7.0\%) had a higher infection rate of Blastocystis than mammals (3.8\%). Blastocystis was found in seven mammal species, reindeer (6.7\%), sika deer (14.6\%), racoon dogs (7.5\%), Arctic foxes (1.9\%), dogs (2.9\%), rats (3.7\%) and rabbits (3.3\%), as well as three bird species, pigeons (2.1\%), chickens (13.0\%) and red crowned cranes (14.0\%). Eight subtypes were identified including ST1 $(n=5)$, ST3 $(n=3)$, ST4 $(n=13)$, ST6 $(n=8)$, ST7 $(n=6)$, ST10 $(n=13)$, ST13 $(n=4)$ and ST14 $(n=2) .64 .8 \%(35 / 54)$ of Blastocystis isolates belonged to potentially zoonotic subtypes.

Conclusions: To our knowledge, this is the first report of Blastocystis in reindeer (ST10 and ST13), rabbits (ST4), racoon dogs (ST3) and Arctic foxes (ST1, ST4 and ST7). The findings of potentially zoonotic subtypes suggest that the animals infected with Blastocystis might pose a threat to human health. These data will improve our understanding of the host range and genetic diversity of Blastocystis, and also help develop efficient control strategies to intervene with and prevent the occurrence of human blastocystosis in the investigated areas.

Keywords: Blastocystis, Subtyping, Mammals, Birds, Zoonotic

\section{Background}

Blastocystis is one of the most common parasites colonizing the intestines of humans and numerous animals [1]. Variable infection rates have been observed in humans: $22-56 \%$ in European countries and $37-100 \%$ in Asian and African countries [2]. The application of PCR-based molecular tools for subtyping Blastocystis isolates has revealed an extensive genetic diversity within

\footnotetext{
* Correspondence: liuaiqin1128@126.com; YangFK99@hotmail.com
${ }^{+}$Jianguang Wang and Baiyan Gong contributed equally to this work.

* Correspondence: liuaiqin1128@126.com; YangFK99@hotmail.com
†Jianguang Wang and Baiyan Gong contributed equally to this work. Department of Parasitology, Harbin Medical University, Harbin 150081, Heilongjiang, China
}

(c) The Author(s). 2018 Open Access This article is distributed under the terms of the Creative Commons Attribution 4.0 International License (http://creativecommons.org/licenses/by/4.0/), which permits unrestricted use, distribution, and reproduction in any medium, provided you give appropriate credit to the original author(s) and the source, provide a link to the Creative Commons license, and indicate if changes were made. The Creative Commons Public Domain Dedication waiver (http://creativecommons.org/publicdomain/zero/1.0/) applies to the data made available in this article, unless otherwise stated. ing of the characteristics of this pathogen, about its host specificity and transmission patterns [3]. Currently, based on sequence analysis of the SSU rRNA gene, at least 17 Blastocystis subtypes have been identified in mammals and birds, with eight subtypes (STs1-8) co-occurring in humans and animals [1]. High similarity or even identity of DNA sequences of Blastocystis isolates from humans and animals suggests the potential of zoonotic transmission [4-7]. Humans and domestic or zoo animals living in close contact have been reported to be infected with the same subtypes, such as ST1 and 
ST2 in zoo keepers and one wombat, and five primate species in Australia [5]; ST2 in children and monkeys in Nepal [8]; ST5 in piggery workers and pigs in Australia [9]; and ST6 in breeders and cattle/goats in Nepal [10, 11]. Thus, understanding infection rates of Blastocystis in a wide range of animal hosts, exploring genetic characterization and assessing zoonotic potential of animal-derived isolates will aid in making effective strategies to intervene with and prevent occurrence of human blastocystosis.

In China to date, Blastocystis infection has been reported in humans and animals distributed in at least 26 and 11 provinces or autonomous regions, respectively [12]. In northeastern China, Blastocystis is prevalent in common livestock such as cattle, sheep, goats and pigs $[12,13]$. This pathogen has also been found in human immunodeficiency virus (HIV)-infected and acquired immunodeficiency syndrome (AIDS) patients (unpublished data) and cancer patients in these areas [14]. However, relatively few data are available on genetic characterization of Blastocystis and subtype distribution in animal hosts. The contribution of animal sources to human infection of Blastocystis remains unclear. Thus, efforts to subtype Blastocystis isolates from under-sampled hosts should be preferentially carried out. The present study provides information regarding infection rates of Blastocystis, host distribution and genetic diversity of subtypes and the zoonotic potential of Blastocystis isolates from various mammal and bird species in northeastern China.

\section{Methods}

\section{Collection of fecal specimens}

A cross-sectional investigation of Blastocystis was carried out on various mammals and birds from May 2015 to October 2017 in Heilongjiang, Liaoning and Jilin provinces of northeastern China. A total of 1265 fecal specimens were collected, with 1080 from 10 mammal species and 185 from eight bird species (Table 1). The vast majority of specimens were from Heilongjiang Province. Three deer species were involved in the present study, including 104 wild reindeer (Rangifer tarandus) and 82 sika deer (Cervus nippon) from farms and 48 red deer (Cervus elqphus) from a zoo (30 from Jilin). Three hundred sixty-seven fur animals were randomly selected from farms, including 40 racoon dogs (Nyctereutes procyonoides) (24 from Jilin), 213 Arctic foxes (Alopex lagopus) (66 from Jilin and 40 from Liaoning) and 114 American minks (Neovison vison) (35 from Jilin and 54 from Liaoning). One hundred thirty-six dogs (Canis lupus familiaris) were included in the present study, constituting 76 pet dogs and 60 farm dogs (12 from Jilin). The remaining 343 mammals and 185 birds were all from Heilongjiang. The mammals comprised 20 horses (Equus caballus) from private owners, 215 rabbits (Oryctolagus cuniculus) from farms and 108 brown rats (Mus musculus), including 23 from a granary, 48 from pig farms and 37 from a sheep farm. The birds comprised 46 chickens (Gallus domesticus), 16 ducks (Anas platyrhynchos domesticus) and 20 geese (Anser domestica) from farms, 47 pigeons (Columba livia) from individual aviaries as well as 43 red crowned cranes (Grus japonensis), 6 common cranes (Grus grus), 4 white-naped cranes (Grus vipio) and 3 Siberian cranes (Grus leucogeranus) from Zhalong National Nature Reserve.

Farmed rabbits and captured free-ranging pigeons were fed alone in each cage for $24 \mathrm{~h}$ and then fecal specimens were collected from the bottom of each cage. All captured wild rats were euthanized by $\mathrm{CO}_{2}$ inhalation and fecal specimens were collected directly from their intestinal and rectal content. For the collection of fecal specimens of the other mammals and birds, we only picked up fresh feces on the top of droppings on the ground after defecation to avoid contamination. All fecal specimens obtained were stored in refrigerators at $-20{ }^{\circ} \mathrm{C}$ for further molecular analysis. No diarrhea was observed in any animal at the time of sampling.

\section{DNA extraction}

To reduce interference from crude fiber and impurities, the fecal specimens were sieved and washed with distilled water by centrifugation at $1500 \times g$ for $10 \mathrm{~min}$. This was done three times at room temperature. Genomic DNA of Blastocystis was extracted from 180-200 mg of each washed fecal pellet using a commercially available kit (QIAamp DNA Mini Stool Kit, Qiagen, Hilden, Germany) according to the manufacturer-recommended procedures. To obtain a high yield of DNA, the lysis temperature was increased to $95{ }^{\circ} \mathrm{C}$ according to the manufacturer's suggestion. Extracted DNA was stored at $-20{ }^{\circ} \mathrm{C}$ until PCR analysis.

\section{PCR amplification and sequencing}

Considering the characterizations of two sets of primers for amplifying the Santín region and the barcode region of the SSU rRNA of Blastocystis described by Wang et al. [12], in the present study all DNA preparations were screened for the presence of Blastocystis by PCR amplification of the Santín region ( a fragment of approximately $500 \mathrm{bp}$ ) [15]. PCR-positive DNA preparations were further analyzed to determine subtypes of Blastocystis isolates by PCR amplification and sequence analysis of the barcode region (a fragment of approximately $600 \mathrm{bp}$ ) according to terminology for Blastocystis subtypes - a consensus $[3,16]$. TaKaRa Taq DNA polymerase (TaKaRa Bio Inc., Tokyo, Japan) was used for all PCR reactions. A negative control (no DNA water control) and a positive control (DNA of a pig-derived Blastocystis isolate) were used in all PCR tests. All PCR products were subjected to electrophoresis in a $1.5 \%$ agarose gel and were 
Table 1 Infection rates and subtype distribution of Blastocystis in various mammals and birds. The novel sequences obtained in the present study are highlighted in bold

\begin{tabular}{|c|c|c|}
\hline Host & $\begin{array}{l}\text { No. positive/total } \\
\text { no. examined (\%) }\end{array}$ & 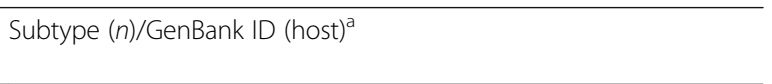 \\
\hline \multicolumn{3}{|l|}{ Mammals } \\
\hline \multirow[t]{2}{*}{ Reindeer (Rangifer tarandus) } & \multirow[t]{2}{*}{ 7/104 (6.7) } & ST10 (3)/KC148207 (Camel); MF541100 (Goat) \\
\hline & & ST13 (4)/MH325366 (Reindeer) \\
\hline Red deer (Cervus elaphus) & $0 / 48$ & \\
\hline \multirow[t]{4}{*}{ Sika deer (Cervus nippon) } & \multirow[t]{4}{*}{ 12/82 (14.6) } & ST10 (8)/KC148207 (Camel); MF541100 (Goat) \\
\hline & & ST14 (2)/KC148206 (Mouflon) \\
\hline & & ST10 (1)/MH325363 (Sika deer) \\
\hline & & ST10 (1)/MH325364 (Sika deer) \\
\hline Racoon dog (Nyctereutes procyonoides) & $3 / 40(7.5)$ & ST3 (3)/KY019163 (Human) \\
\hline \multirow[t]{3}{*}{ Arctic fox (Alopex lagopus) } & \multirow[t]{3}{*}{$4 / 213(1.9)$} & ST1 (2)/U51151 (Human); EU445488 (Monkey) \\
\hline & & ST4 (1)/AY135408 (Rat) \\
\hline & & ST7 (1)/MH325365 (Arctic Fox) \\
\hline American mink (Neovison vison) & 0/114 (0) & \\
\hline \multirow[t]{2}{*}{ Domestic dog (Canis lupus familiaris) } & \multirow[t]{2}{*}{ 4/136 (2.9) } & ST1 (3)/MF669063 (Human) \\
\hline & & ST4 (1)/AY135408 (Rat) \\
\hline Horse (Equus caballus) & $0 / 20$ & \\
\hline Brown rat (Mus musculus) & 4/108 (3.7) & ST4 (4)/AB071000 (Rat) \\
\hline New Zealand white rabbit (Oryctolagus cuniculus) & $7 / 215(3.3)$ & $\begin{array}{l}\text { ST4 (7)/MF669075 (Human); EU427516 (Kangaroo); } \\
\text { AY590113 (Rat); MF541101 (Goat) }\end{array}$ \\
\hline Subtotal & $41 / 1080(3.8)$ & ST1 (5); ST3 (3); ST4 (13); ST7 (1); ST10 (13); ST13 (4); ST14 (2) \\
\hline \multicolumn{3}{|l|}{ Birds } \\
\hline Domestic duck (Anas platyrhynchos domesticus) & $0 / 16$ & \\
\hline Domestic goose (Anser domestica) & $0 / 20$ & \\
\hline Pigeon (Columba livia) & $1 / 47(2.1)$ & ST6 (1)/KT438692 (Human); AB107972 (Partridge) \\
\hline \multirow[t]{3}{*}{ Domestic chicken (Gallus domesticus) } & \multirow[t]{3}{*}{$6 / 46(13.0)$} & ST6 (1)/KT438692 (Human); AB107972 (Partridge) \\
\hline & & ST6 (2)/KT438697 (Human); \\
\hline & & ST7 (3)/EF079872 (Human) \\
\hline \multirow[t]{2}{*}{ Red crowned crane (Grus japonensis) } & \multirow[t]{2}{*}{ 6/43 (14.0) } & ST6 (4)/KT438692 (Human); AB107972 (Partridge) \\
\hline & & ST7 (2)/EF079872 (Human) \\
\hline Common crane (Grus grus) & $0 / 6$ & \\
\hline White-naped crane (Grus vipio) & $0 / 4$ & \\
\hline Siberian crane (Grus leucogeranus) & $0 / 3$ & \\
\hline Subtotal & $13 / 185(7.0)$ & ST6 (8); ST7 (5) \\
\hline Total & $54 / 1265(4.3)$ & ST1 (5); ST3 (3); ST4 (13); ST6 (8); ST7 (6); ST10 (13); ST13 (4); ST14 (2) \\
\hline
\end{tabular}

Abbreviations: $n$ number of individuals

${ }^{a}$ Accession no. indicating the sequences downloaded from GenBank, which have $100 \%$ homology with the sequences obtained in the present study

visualized after staining the gel with GelStrain (TransGen Biotech, Beijing, China).

\section{Nucleotide sequencing and analyzing}

All positive PCR products of the expected size were sequenced with the primers given in [16] on an ABI PRISM 3730 XL DNA Analyzer (Applied Biosystems, Foster, CA, USA), using a BigDye Terminator v.3.1 Cycle
Sequencing Kit (Applied Biosystems). Accuracy of the sequencing data was confirmed by sequencing the PCR products in both directions. Two new PCR products were sequenced for some DNA preparations, from which we obtained sequences different to those published in GenBank. Nucleotide sequences obtained in the present study were subjected to BLAST searches (http://www.ncbi.nlm.nih.gov/blast/) and then aligned 
and analyzed with each other and reference sequences downloaded from GenBank by using the program Clustal X 1.83 (http://www.clustal.org/). Subtypes of Blastocystis isolates were identified according to the proposed standard of Blastocystis terminology [3].

\section{Results}

\section{Infection rates of Blastocystis}

$4.3 \%$ (54/1265) of fecal specimens were positive for Blastocystis by PCR amplification of the Santín region of the SSU rRNA gene. Birds $(7.0 \%, 13 / 185)$ had higher infection rates than mammals $(3.8 \%, 41 / 1080)$, with no statistically significant difference between them $\left(\chi^{2}=3.625\right.$, $P>0.05)$. Blastocystis was only found in seven mammal species, reindeer $(6.7 \%, 7 / 104)$, sika deer $(14.6 \%, 12 / 82)$, racoon dogs $(7.5 \%, 3 / 40)$, Arctic foxes $(1.9 \%, 4 / 213)$, domestic dogs $(2.9 \%, 4 / 136)$, brown rats $(3.7 \%, 4 / 108)$ and New Zealand white rabbits $(3.3 \%, 7 / 215)$, as well as three bird species, pigeons $(2.1 \%, 1 / 47)$, chickens $(13.0 \%, 6 / 46)$ and red crowned cranes $(14.0 \%, 6 / 43)$ (Table 1).

\section{Subtypes of Blastocystis isolates}

All positive DNA preparations in the Santín region were successfully amplified and sequenced in the barcode region. By sequence analysis of the barcode region, eight subtypes were identified out of 54 Blastocystis isolates, including ST1 $(n=5)$, ST3 $(n=3)$, ST4 $(n=13)$, ST7 $(n=1), \operatorname{ST} 10(n=13), \operatorname{ST} 13(n=4)$ and ST14 $(n=2)$ in mammals, and ST6 $(n=8)$, ST7 $(n=5)$ in birds, with ST7 in both mammals and birds. Among them, ST4 was found in rabbits, rats, foxes and dogs, showing the widest host distribution. Either ST4 or ST10 shared the largest percentage of Blastocystis isolates $(24.1 \%, 13 / 54)$. Meanwhile, it was observed that $64.8 \%$ (35/54) of Blastocystis isolates belonged to potentially zoonotic subtypes based on the fact that STs1-8 has been found in humans and animals. Detailed information on subtype distribution of Blastocystis by host and by geography is summarized in Tables 1 and 2, respectively.

\section{Genetic diversity of Blastocystis subtypes}

A total of 15 representative sequences were obtained from 54 Blastocystis isolates in the present study. Among them, 11 sequences have been described previously, with seven of them being reported in humans. The remaining four novel sequences were composed of ST7 $(n=1)$, ST10 $(n=2)$ and ST13 $(n=1)$ (Table 1). The ST7 sequence (MH325365) from a fox had two base differences compared to that (KP233737) from a duck in the Philippines. There were two base differences between the two ST10 sequences (MH325363 and MH325364) from sika deer, and both of them had a base variation compared to that (KC148207) from a camel in Libya. The ST13 sequence (MH325366) from reindeer had the largest similarity with that (KC148209) from a mouse deer (Tragulus javanicus) in the UK, with 10 base differences.

\section{Discussion}

Infection rates of Blastocystis vary in mammals and birds between and within countries worldwide [17] and is as high as $100 \%$ in some studies, such as in dogs in

Table 2 Subtype distribution of Blastocystis by geography and host in northeastern China

\begin{tabular}{|c|c|c|c|c|c|c|c|c|c|}
\hline \multirow[t]{2}{*}{ Location } & \multirow[t]{2}{*}{ Host } & \multicolumn{8}{|c|}{ Subtype } \\
\hline & & ST1 & ST3 & ST4 & ST6 & ST7 & ST10 & ST13 & ST14 \\
\hline \multirow[t]{10}{*}{ Heilongjiang } & Reindeer & $-{ }^{a}$ & - & - & - & - & 3 & 4 & - \\
\hline & Sika deer & - & - & - & - & - & 6 & - & - \\
\hline & Racoon dog & - & 1 & - & - & - & - & - & - \\
\hline & Arctic fox & 2 & - & 1 & - & - & - & - & - \\
\hline & Domestic dog & 1 & - & 1 & - & - & - & - & - \\
\hline & Brown rat & - & - & 4 & - & - & - & - & - \\
\hline & New Zealand white rabbit & - & - & 7 & - & - & - & - & - \\
\hline & Domestic chicken & - & - & - & 3 & 3 & - & - & - \\
\hline & Pigeon & - & - & - & 1 & - & - & - & - \\
\hline & Red crowned crane & - & - & - & 4 & 2 & - & - & - \\
\hline \multirow[t]{2}{*}{ Jilin } & Sika deer & - & - & - & - & - & 4 & - & 2 \\
\hline & Domestic dog & 2 & - & - & - & - & - & - & - \\
\hline \multirow[t]{2}{*}{ Liaoning } & Racoon dog & - & 2 & - & - & - & - & - & - \\
\hline & Arctic fox & - & - & - & - & 1 & - & - & - \\
\hline Total & & 5 & 3 & 13 & 8 & 6 & 13 & 4 & 2 \\
\hline
\end{tabular}

${ }^{\mathrm{a}}$ Negative results denoted by $\mathrm{n}$-dash 
Australia and in birds in Malaysia [18, 19]. In the investigated areas, Blastocystis was found in seven mammal species and three bird species, with infection rates ranging from 1.9 to $14.6 \%$. There was an absence of Blastocystis in horses, red deer, minks, ducks, geese and three crane species. This might be related to the small number of collected specimens and/or a low prevalence of Blastocystis in these animals.

In the present study, eight subtypes (ST1, ST3, ST4, ST6, ST7, ST10, ST13 and ST14) were identified. Among them, ST10 was the most common in deer $(68.4 \%, 13 / 19)$. Previous studies have revealed that ST10 is found commonly in some livestock (cattle, sheep and goats) and sporadically in some herbivorous animals including camels, alpacas, wild yaks, ponies, kangaroos, giraffes, wild asses, bisons and oryxes [1, 12, 17, 20, 21]. This subtype is also identified in pigs and ostriches from China, cats from the USA and dogs from France [12, 20-22]. In the present study, ST13 and ST14 were identified in reindeer and sika deer for the first time, respectively. ST13 is actually a rare subtype and previously had only been found in mouse deer from the UK, kangaroos and quokkas from Australia, and monkeys from China and France [5, 17, 21, 23, 24]. ST14 is similar to ST10 in host range. It is composed of Blastocystis isolates from various herbivorous animals including some common livestock (cattle, sheep and goats), and some artiodactyla (camels, alpacas, giraffes, bushbucks, mouflons, common elands, brindled wildebeests and bisons) [1, 12, 17, 21]. The true host range of these subtypes can be defined by subtyping a large number of Blastocystis isolates from different hosts and areas in the future. To date, a total of five subtypes (ST4, ST5, ST10, ST13 and ST14) have been identified in six deer species including reindeer involved in the present study [17, 21, 23].

Dogs have a long association with human behavior, such as companionship, protection and herding, as well as aiding handicapped individuals. However, potentially zoonotic subtypes of Blastocystis have been found in dogs and their owners in Australia (ST1, ST3 and ST4), the Philippines (ST1 to ST5) and Turkey (ST1 and ST7) $[18,25,26]$, suggesting the possibility of the dogs being involved in the transmission of Blastocystis to humans. In the present study, ST1 and ST4 were identified in dogs. To date, eight subtypes (ST1 to ST7 and ST10) have been identified in these animals [20, 25-27]. However, the subtype constitution is observed to be different, such as ST1, ST4, ST5 and ST6 in India, and ST2 and ST10 in the USA $[22,27]$. This might be closely related to the fact that coprophagia is a common practice in dogs, especially stray dogs. They could have acquired Blastocystis infections with various subtypes by exposure to fecal materials from animal hosts and humans in their environment. Meanwhile, this also could explain the reason that no predominant or specific subtypes are identified in the overall canine population [1, 18]. Of course, the mechanical transport of Blastocystis in dogs cannot be ruled out. It has been reported that dogs can serve as a mechanical vector of possibly viable eggs for a variety of helminth parasites [28]. Longitudinal studies of Blastocystis in dogs are needed before a definitive conclusion can be drawn.

ST4 is the most common in rodents among the five subtypes identified (ST2 to ST5 and ST17) [1, 17]. As expected, ST4 was identified in brown rats in the investigated areas. ST4 is also one of the four most common subtypes in humans (ST1 to ST4) [29]. Besides rodents and humans, this subtype has been found in non-human primates (ring-tailed lemurs, woolly monkeys, siamangs), giraffes, kangaroos, dogs and a snow leopard as well as ostriches [1, 7, 23, 27]. In the present study, ST4 was identified in rabbits and foxes for the first time, expanding its host range.

ST6 and ST7 are usually isolated from bird reservoir hosts [1]. In the present study, ST6 and ST7 were identified in chickens and red crowned cranes while ST6 was found in one pigeon. Currently, although seven subtypes (ST1, ST2, ST4 to ST7 and ST10) have been identified in birds $[1,21,30]$, ST6 and ST7 are still the most common subtypes in birds and generally considered as avian subtypes [7]. Besides birds, the two subtypes are occasionally found in some mammals: ST6 in pigs, cattle, goats and dogs $[12,27]$ and ST7 in pigs, goats, cynomolgus monkeys, ruffed lemurs and dogs [1, 12, 17, 25, 31]. In humans, ST6 and ST7 only constitute a small share (approximately 9\%) of cases of blastocystosis [32].

In the present study, $64.8 \%(35 / 54)$ of Blastocystis isolates belonged to potentially zoonotic subtypes and $80.0 \%(28 / 35)$ of the sequences of these subtypes have been described in humans, including ST1 $(n=5)$, ST3 $(n=3)$, ST4 $(n=7)$, ST6 $(n=8)$ and ST7 $(n=5)$ (Table 1). In several previous studies of the natural infection of Blastocystis in mammals and birds, all Blastocystis isolates are identified as zoonotic subtypes, such as in dogs from India and the Philippines [26, 27], in rats from Colombia and Indonesia [33, 34] and in birds from Japan and Malaysia [19, 35]. Undoubtedly, the percentage of zoonotic subtypes of Blastocystis isolates in animals is an important parameter to assess the risk of zoonotic transmission of blastocystosis in a specific area. Meanwhile, it is reasonable and scientific to understand the infection rates of this pathogen in animal hosts. The low prevalence suggests a minor risk of zoonotic transmission, but more investigation into the epidemiological factors associated with Blastocystis transmission is needed to more accurately assess the potential for zoonotic transmission. In the present study, the vast majority of animals were domestic and captive farmed animals. They were from 
farms, zoos or individual owners. Thus, the people who have close contact with animals for occupational or recreational reasons are at a high risk of acquiring Blastocystis infection. In fact, high prevalence of Blastocystis infections has been reported among zoo keepers and the same subtypes have been found in humans and animals living in close contact $[5,8-11,36]$. Meanwhile, Blastocystis in animal feces can enter streams and rivers through surface run-off after a heavy rainfall, which causes water contamination downstream and a wide geographical spread of Blastocystis.

\section{Conclusions}

The present study describes the occurrence, subtype distribution and genetic characterization of Blastocystis in various mammal and bird species in northeastern China. Average infection rates of Blastocystis were $3.8 \%$ in mammals and $7.0 \%$ in birds. Eight subtypes were identified, with subtype overlaps being observed in some host species. $64.8 \%$ of subtypes were potentially zoonotic, suggesting that animals infected with Blastocystis might pose a threat to human health. Blastocystis was identified for the first time in reindeer (ST10 and ST13), rabbits (ST4), racoon dogs (ST3) and Arctic foxes (ST1, ST4 and ST7), expanding the host range of Blastocystis. Four novel nucleotide sequences of Blastocystis have never been reported before. These data obtained in the present study increase our understanding of the host range and genetic diversity of Blastocystis and will help develop efficient control strategies to intervene with and prevent the occurrence of blastocystosis in the investigated areas.

\section{Abbreviations \\ AIDS: Acquired immunodeficiency syndrome; BLAST: Basic local alignment search tool; HIV: Human immunodeficiency virus; PCR: Polymerase chain reaction; SSU: Small subunit}

\section{Funding}

The study was supported by the Natural Science Foundation of Heilongjiang Province (H2017006) and the Heilongjiang Province Education Bureau (12531266). The funders had no role in study design, data collection and analysis, decision to publish, or preparation of the manuscript.

\section{Availability of data and materials}

All data generated or analyzed during this study are included in this published article. Sequences were submitted to the GenBank database under the accession numbers MH325363-MH325366.

\section{Authors' contributions}

Experiments were conceived and designed by $\mathrm{AL}$ and $\mathrm{FY}$. Experiments were performed by JW, BG, XL, Wei $Z$ and TB. The data were analyzed by JW and BG. Weizhe $Z$ contributed reagents/materials/analysis tools. The manuscript was written by JW and BG, and revised by AL and FY. All authors read and approved the final manuscript.

\section{Ethics approval}

All animals were handled and cared for according to the Chinese Laboratory Animal Administration Act of 1998. The research protocol was reviewed and approved by the Research Ethics Committee and the Animal Ethical Committee of Harbin Medical University.
Consent for publication

Not applicable.

\section{Competing interests}

The authors declare that they have no competing interests.

\section{Publisher's Note}

Springer Nature remains neutral with regard to jurisdictional claims in published maps and institutional affiliations.

Received: 29 May 2018 Accepted: 10 September 2018

Published online: 20 September 2018

\section{References}

1. Cian A, El Safadi D, Osman M, Moriniere R, Gantois N, Benamrouz-Vanneste $\mathrm{S}$, et al. Molecular epidemiology of Blastocystis sp. in various animal groups from two French zoos and evaluation of potentially zoonotic risk. PLoS One. 2017;12:e0169659.

2. Forsell J, Bengtsson-Palme J, Angelin M, Johansson A, Evengard B, Granlund $M$. The relation between Blastocystis and the intestinal microbiota in Swedish travellers. BMC Microbiol. 2017:17:231.

3. Stensvold CR, Suresh GK, Tan KS, Thompson RC, Traub RJ, Viscogliosi E. Terminology for Blastocystis subtypes - a consensus. Trends Parasitol. 2007: 23:93-6.

4. Parkar U, Traub RJ, Kumar S, Mungthin M, Vitali S, Leelayoova S, et al. Direct characterization of Blastocystis from feces by PCR and evidence of zoonotic potential. Parasitology. 2007;134:359-67.

5. Parkar U, Traub RJ, Vitali S, Elliot A, Levecke B, Robertson I, et al. Molecular characterization of Blastocystis isolates from zoo animals and their animalkeepers. Vet Parasitol. 2010;169:8-17.

6. Rivera WL. Phylogenetic analysis of Blastocystis isolates from animal and human hosts in the Philippines. Vet Parasitol. 2008;156:178-82.

7. Stensvold CR, Alfellani MA, Norskov-Lauritsen S, Prip K, Victory EL, Maddox C, et al. Subtype distribution of Blastocystis isolates from synanthropic and zoo animals and identification of a new subtype. Int J Parasitol. 2009;39:473-9.

8. Yoshikawa WZ, Pandey K, Pandey BD, Sherchand JB, Yanagi T, et al. Molecular characterization of Blastocystis isolates from children and rhesus monkeys in Kathmandu. Nepal. Vet Parasitol. 2009;160:295-300.

9. Wang W, Owen H, Traub RJ, Cuttell L, Inpankaew T, Bielefeldt-Ohmann H. Molecular epidemiology of Blastocystis in pigs and their in-contact humans in Southeast Queensland, Australia, and Cambodia. Vet Parasitol. 2014;203:264-9.

10. Lee LI, Chye TT, Karmacharya BM, Govind SK. Blastocystis sp.: waterborne zoonotic organism, a possibility? Parasit Vectors. 2012:5:130

11. Lee IL, Tan TC, Tan PC, Nanthiney DR, Biraj MK, Surendra KM, et al. Predominance of Blastocystis sp. subtype 4 in rural communities, Nepal. Parasitol Res. 2012;110:1553-62

12. Wang J, Gong B, Yang F, Zhang W, Zheng Y, Liu A. Subtype distribution and genetic characterizations of Blastocystis in pigs, cattle, sheep and goats in northeastern China's Heilongjiang Province. Infect Genet Evol. 2018;57:171-6.

13. Zhu W, Tao W, Gong B, Yang H, Li Y, Song M, et al. First report of Blastocystis infections in cattle in China. Vet Parasitol. 2017;246:38-42.

14. Zhang W, Ren G, Zhao W, Yang Z, Shen Y, Sun Y, et al. Genotyping of Enterocytozoon bieneusi and subtyping of Blastocystis in cancer patients: relationship to diarrhea and assessment of zoonotic transmission. Front Microbiol. 2017:8:1835.

15. Santín M, Gómez-Muñoz MT, Solano-Aguilar G, Fayer R. Development of a new PCR protocol to detect and subtype Blastocystis spp. from humans and animals. Parasitol Res. 2011;109:205-12.

16. Scicluna SM, Tawari B, Clark CG. DNA barcoding of Blastocystis. Protist. 2006; 157:77-85.

17. Alfellani MA, Taner-Mulla D, Jacob AS, Imeede CA, Yoshikawa H, Stensvold $C R$, et al. Genetic diversity of Blastocystis in livestock and zoo animals. Protist. 2013;164:497-509.

18. Nagel R, Cuttell L, Stensvold CR, Mills PC, Bielefeldt-Ohmann H, Traub RJ. Blastocystis subtypes in symptomatic and asymptomatic family members and pets and response to therapy. Intern Med J. 2012:42:1187-95.

19. Chandrasekaran H, Govind SK, Panchadcharam C, Bathmanaban P, Raman K, Thergarajan G. High lipid storage in vacoular forms of subtype 6 Blastocystis sp. in ostrich. Parasit Vectors. 2014;7:469. 
20. Osman M, Bories J, El Safadi D, Poirel MT, Gantois N, Benamrouz-Vanneste S, et al. Prevalence and genetic diversity of the intestinal parasites Blastocystis sp. and Cryptosporidium spp. in household dogs in France and evaluation of zoonotic transmission risk. Vet Parasitol. 2015;214:167-70.

21. Zhao GH, Hu XF, Liu TL, Hu RS, Yu ZQ, Yang WB, et al. Molecular characterization of Blastocystis sp. in captive wild animals in Qinling Mountains. Parasitol Res. 2017;116:2327-33.

22. Ruaux CG, Stang BV. Prevalence of Blastocystis in shelter-resident and client-owned companion animals in the US Pacific Northwest. PLoS One. 2014;9:e107496.

23. Roberts T, Stark D, Harkness J, Ellis J. Subtype distribution of Blastocystis isolates from a variety of animals from New South Wales, Australia. Vet Parasitol. 2013;196:85-9.

24. Alfellani MA, Jacob AS, Perea NO, Krecek RC, Taner-Mulla D, Verweij JJ, et al. Diversity and distribution of Blastocystis sp. subtypes in non-human primates. Parasitology. 2013;140:966-71.

25. Eroglu $F$, Koltas IS. Evaluation of the transmission mode of $B$. hominis by using PCR method. Parasitol Res. 2010;107:841-5.

26. Belleza ML, Reyes JC, Tongol-Rivera PN, Rivera WL. Subtype analysis of Blastocystis sp. isolates from human and canine hosts in an urban community in the Philippines. Parasitol Int. 2016;65:291-4.

27. Wang W, Cuttell L, Bielefeldt-Ohmann H, Inpankaew T, Owen H, Traub RJ. Diversity of Blastocystis subtypes in dogs in different geographical settings. Parasit Vectors. 2013;6:215.

28. Nijsse R, Mughini-Gras L, Wagenaar JA, Ploeger HW. Coprophagy in dogs interferes in the diagnosis of parasitic infections by faecal examination. Vet Parasitol. 2014;204:304-9.

29. Clark CG, van der Giezen M, Alfellani MA, Stensvold CR. Recent developments in Blastocystis research. Adv Parasitol. 2013;82:1-32.

30. Yoshikawa H, Abe N, Wu Z. Genomic polymorphism among Blastocystis isolates and development of PCR-based identification of zoonotic isolates. J Eukaryot Microbiol. 2003;50:710-1.

31. Zanzani SA, Gazzonis AL, Epis S, Manfredi MT. Study of the gastrointestinal parasitic fauna of captive non-human primates (Macaca fascicularis). Parasitol Res. 2016;115:307-12.

32. Alfellani MA, Stensvold CR, Vidal-Lapiedra A, Onuoha ES, Fagbenro-Beyioku AF, Clark CG. Variable geographic distribution of Blastocystis subtypes and its potential implications. Acta Trop. 2013;126:11-8.

33. Ramírez JD, Sánchez LV, Bautista DC, Corredor AF, Flórez AC, Stensvold CR. Blastocystis subtypes detected in humans and animals from Colombia. Infect Genet Evol. 2013;22:223-8.

34. Yoshikawa H, Tokoro M, Nagamoto T, Arayama S, Asih PB, Rozi IE, et al. Molecular survey of Blastocystis sp. from humans and associated animals in an Indonesian community with poor hygiene. Parasitol Int. 2016;65:780-4.

35. Yoshikawa $\mathrm{H}$, Abe N, Wu Z. PCR-based identification of zoonotic isolates of Blastocystis from mammals and birds. Microbiology. 2004;150:147-51.

36. Salim HR, Kumar GS, Vellayan S, Mak JW, Anuar AK, Init I, et al. Blastocystis in animal handlers. Parasitol Res. 1999;85:1032-3.

Ready to submit your research? Choose BMC and benefit from:

- fast, convenient online submission

- thorough peer review by experienced researchers in your field

- rapid publication on acceptance

- support for research data, including large and complex data types

- gold Open Access which fosters wider collaboration and increased citations

- maximum visibility for your research: over $100 \mathrm{M}$ website views per year

At BMC, research is always in progress.

Learn more biomedcentral.com/submissions 